\title{
SISTEM APLIKASI WEBSITE SURAT MASUK DAN KELUAR ( STUDI KASUS DIKELURAHAN PANJUNAN)
}

\author{
Fairuz Maulani Rifani ${ }^{1}$, Wiwiek Nurkomala Dewi ${ }^{2}$, Agus Sevtiana ${ }^{3}$ \\ Sekolah Tnggi Manajemen Informatika dan Komputer CIC Cirebon \\ Jl. Kesambi 202, Kota Cirebon, Jawa Barat Telp: (0231) 220350 \\ e-mail: fairuzmaulanar@gmail.com ${ }^{1}$,wiwiek.nurkomala.dewi@cic.ac.id ${ }^{2}$ A.sevtiana@gmail.com ${ }^{3}$
}

\begin{abstract}
Di zaman modern seperti sekarang ini penggunaan teknologi sangatlah penting untuk masyarakat luas, terutama yang berinstansi di pemerintahan. Namun pada kenyataannya masih banyak yang masih menggunakan menulis data (manual) dalam pelaksanaannya. Oleh karena itu kami ingin membuat suatu aplikasi berbasis website untuk memudahkan bagian pelayanan membuat, merekap, dan mencari data informasi yang bernama sistem aplikasi website surat masuk dan surat keluar di Kelurahan Panjunan. Diharapkan dengan adanya sistem ini Kelurahan Panjunan dapat bisa memanfaatkan teknologi lebih banyak lagi, bukan hanya bagian pelayanan dan lurah tetapi seluruh pegawai panjunan bisa merasakannya nanti. Dalam pembuatan aplikasi, pertama-tama kami melakukan teknik pengumpulan data untuk mengetahui keadaan dilapangan dan menanyakan keadaan secara langsung dengan yang bersangkutan. Setelah itu kami akan mencari rujukan dalam memperoleh data lebih dalam. Lalu kami akan melakukan tahap penilitian di Kelurahan Panjunan untuk menerapkan sistem yang akan kami buat. Tujuan dari dibuat aplikasi ini diharapkan bagian pelayanan dapat menggunakan teknologi yang ada, mempermudah pekerjaan dalam mendata surat dan dapat mengelola data surat secara sistematis tanpa harus membuka buku register. Dan sebagai Lurah hanya bisa melihat rekapan surat masuk dan keluar yang sudah dibuat.Manfaat dari adanya teknologi di dunia instansi terutama pemerintahan adalah untuk mempermudah para karyawan dalam pekerjaan, selain itu agar bisa menghubungi satu dengan yang lainnya tanpa harus mendatangi karyawan tersebut. Semoga dengan adanya aplikasi ini Kelurahan Panjunan juga membuat aplikasi lainnya untuk mempermudah pegawai dan juga untuk masyarakat umum agar masyarakat juga bisa mengetahui informasi pembuatan surat surat yang berasa di Kelurahan Panjunan secara menyeluruh dan tidak ada lagi kesalahan antar masyarakat dan pegawai Kelurahan Panjunan.
\end{abstract}

Kata Kunci: Sistem, Website, Teknologi, Aplikasi, Data

\begin{abstract}
Abstrak
In modern times as of now the use of technology is very important for the wider community, especially those that are in government. But in reality there are still many who still use writing data (manual) in the implementation. Therefore we want to create a website-based application to make it easier for the service to create, recap, and search for information data called the website application system for incoming and outgoing mail in Panjunan Village. It is hoped that with this system, Panjunan Urban Village can use more technology, not just the service and village chief,but all Panjunan employees can feel it later. In making an application, we first conduct data collection techniques to find out the situation in the field and ask the situation directly with the person concerned. After that we will look for references in obtaining deeper data. Then we will conduct a research phase at Panjunan Village to implement the system that we will make. The purpose of this application is expected to be part of the service can use existing technology, simplify the work in registering letters and can manage mail data systematically without having to open the register book. And as the Lurah can only see the incoming and outgoing letters that have been made. The benefits of the existence of technology in the world of institutions, especially government, are to make it easier for employees at work, in addition to being able to contact one another without having to go to the employee. Hopefully with this application, Panjunan Urban Village also makes other applications to facilitate employees and also for the general public so that the community can also find information on making letters that feel in the Panjunan District thoroughly and there are no more mistakes between the community and employees of Panjunan Village.
\end{abstract}

Keywords: System, Website, Technology, Application, Data 


\section{Pendahuluan}

\subsection{Latar Belakang}

Dalam era zaman modern ini, teknologi sangat pesat keberadaannya didalam kehidupan masyarakat melalui berbagai bidang seperti instansi pemerintahan. Di dalam instansi pemerintah sekarang dituntut untuk bisa menggunakan teknologi didalam pekerjaan sehari-hari dan diharapkan meminimalisir secara manual.

Sistem Pengelolaan Surat Masuk dan Keluar di Kelurahan Panjunan masih menggunakan secara manual, yang berarti data surat harus ditulis di pendataan buku register. Dalam pencatatan surat masuk dan keluar masih ditemukan beberapa kelemahan yaitu harus mengambil buku register dahulu lalu mencatatnya secara manual, belum lagi masih terdapat penulisan yang tidak jelas atau tidak terbaca sehingga akan menyulitkan pembaca jika ingin melihat atau merangkap data surat masuk dan keluar. Kemudian data surat tersebut harus ditulis di surat disposisi agar dapat diselesaikan suatu surat masuk dan keluar sesuai kehendak pimpinan.

Maka dari itu kita ingin membuat sebuah sistem yang bertujuan untuk memudahkan pegawai bagian pelayanan dalam pekerjaan menyurat yaitu membuat sistem aplikasi surat masuk dan keluar berbasis website. Di dalam sistem ini bagian pelayanan hanya memasukkan atau input data surat masuk dan keluar melalui website yang lebih cepat dan effisien daripada harus mengambil buku register surat dan menulisnya. Dan yang menggunakan sistem ini adalah admin (bagian pelayanan) yang biasa melakukan pengisian data surat.

Selain itu dalam aplikasi surat masuk dan keluar terdapat data pegawai di Kelurahan Panjunan Kota Cirebon, lalu terdapat visi dan misi Kelurahan Panjunan yang berada di beranda login dan juga terdapat galeri foto kegiatan pegawai Kelurahan Panjunan saat bertugas di Kantor maupun diluar Kantor.

Kelurahan Panjunan berada di Jalan Sisingamangaraja No 25 Kelurahan Panjunan Kecamatan Lemahwungkuk Kota Cirebon. Setiap hari biasanya ada surat masuk yang biasanya juga ditujukan untuk pelaksana tugas (plt) Lurah Panjunan, lalu ketika surat sudah dikasih oleh bagian pelayanan maka bagian pelayanan akan menulis data surat masuk ke buku register dan surat disposisi ketika tidak ada pekerjaan.

Diharapkan dengan adanya aplikasi sistem surat masuk dan keluar berbasis website maka mempermudah pegawai bagian pelayanan untuk mengisi data surat tanpa harus mengambil dan mencatat data surat di buku register dan surat disposisi. Dan jika ingin melihat surat tersebut tak perlu mengambil buku binder surat, cukup dengan melihat didata surat lalu melihat foto diview agar mempermudah proses pengecekan surat. Maka dari itu dari penjabaran yang sudah disampaikan kami akan memberi judul projek "Aplikasi Berbasis Website Surat Masuk Dan Keluar Di Kelurahan Panjunan Kota Cirebon".

\subsection{Identifikasi Masalah}

Berdasarkan uraian latar belakang masalah tersebut, penulis membuat identifikasi masalah sebagai berikut :

1. Pendataan surat masuk dan keluar di Kelurahan Panjunan Kota Cirebon belum berbasis komputerisasi .

2. Bagaimana membuat sistem aplikasi surat masuk dan keluar serta menghasilkan informasi laporan berbasis web?

3. Belum adanya sistem aplikasi surat masuk dan keluar yang dapat memberikan informasi secara cepat karena harus mencari tanggal pencatatan data surat

\subsection{Batasan Masalah}

Adapun batasan masalah yang penulis lakukan untuk pembuatan aplikasi dalam penelitian ini sebagai berikut

1. Perancangan aplikasi surat masuk dan keluar berbasis website menggunakan bahasa pemrograman PHP.

2. Pengguna (User) Aplikasi yaitu Pegawai Kantor Kelurahan Bagian Pelayanan Kelurahan Panjunan dan Lurah dapat menggunakan aplikasi tersebut.

3. Proses penyimpanan data mengunakan database MySQL dan aplikasi ini bisa menghasilkan laporan surat masuk dan keluar secara periode. 


\subsection{Tujuan}

Tujuan dibuatnya aplikasi surat masuk dan keluar adalah:

1. Mempermudah pendataan data surat masuk dan keluar terutama di bagian Pelayanan.

2. Mencegah terjadinya kesalahan pendataan surat masuk dan keluar.

3. Mempermudah mencari data surat yang diinput dan menghasilkan data surat per periode sesuai kebutuhan di Kelurahan Panjunan

\section{Landasan Teori}

\subsection{Pengertian Sistem}

Sistem berasal dari bahasa Latin (systēma) dan bahasa Yunani (sustēma) adalah suatu kesatuan yang terdiri komponen atau elemen yang dihubungkan bersama untuk memudahkan aliran informasi, materi atau energi untuk mencapai suatu tujuan.

\subsection{Pengertian Administrasi}

Pengertian administrasi secara umum adalah suatu bentuk usaha dan kegiatan yang berkaitan dengan pengaturan kebijaksanaan untuk mencapai tujuan. Pengertian administrasi secara sempit ialah suatu bentuk kegiatan yang meliputi catat-mencatat, surat-menyurat, pembukuan sederhana, ketik-mengetik, dan sebagainya yang mempunyai sifat teknis ketatausahaan.

\subsection{Website}

Website atau juga di sebut Web adalah halaman yang di tampilkan di internet yang memuat informasi tertentu (khusus).web pertama kali diperkenalkan pada tahun 1992. Hal ini sebagai hasil usaha pengembangan yang dilakukan CERN di Swiss.Internet dan web adalah dua hal yang berbeda. Internet yaitu yang dapat menampilkan web-nya, sedangkan web adalah yang ditampilkannya yang berupa susunan dari halaman-halaman yangmenggunakan teknologi Web dan saling berkaitan satu sama lain. Word Wide Web atau Web adalah sub sistem dari internet.

\subsection{PHP (Hypertext Preprocessor)}

Hypertext Preprocessor atau di singkat PHP adalah suatu bahasa pemrograman yang digunakan untuk membuat web dinamis, walau bisa juga digunakan untuk membuat program lain. Tentunya bahasa pemerograman PHP berbeda dengan HTML, pada PHP Script/kode yang di buat tidak dapat di tampilkan pada halaman/muka website begitu saja, tapi harus diproses terlebih dahulu oleh web server lalu di tampilkan dalam bentuk halaman website di web browser, Script PHP juga dapat di sisipkan pada HTML dan script PHP selalu diawali dengan <? php dan di akhiri dengan ?>. Manajamen database yang biasanya digunakan untuk pemerograman PHP misalnya seperti MySQL, tapi ada juga yang menggunakan Oracle, Microsoft Access, dan lain-lain. PHP disebut juga sebagai bahasa pemerograman script server side, karena PHP di proses pada komputer server.

\subsection{MYSQL}

MySQL adalah sebuah perangkat lunak system manajemen basis data SQL (DBMS) yang multithread, dan multi-user.MySQL adalah implementasi dari system manajemen basis data relasional (RDBMS). MySQL dibuah oleh TcX dan telah dipercaya mengelola system dengan 40 buah database berisi 10.000 tabel dan 500 di antaranya memiliki 7 juta baris.

\subsection{Sublime Text}

Sublime Text adalah aplikasi editor untuk kode dan teks yang dapat berjalan diberbagai platform operating system dengan menggunakan teknologi Phyton API.

\subsection{Pengertian Surat}

Menurut Kamus Besar Bahasa Indonesia arti Surat adalah alat komunikasi yang mempergunakan bahasa tulisan di atas lembaran kertas yang sangat erat hubungannya dengan kehidupan manusia.. Dalam kegiatan organisasi, surat paling banyak digunakan untuk menyampaikan informasi.

Secara umum Surat masuk adalah semua tulisan dinas atau surat pribadi yang diterima instansi/pihak lain untuk disampaikan kepada pejabat yang tercantum pada alamat, baik yang tercantum pada sampul maupun pada tulisan dinas itu sendiri. 
Surat keluar adalah semua tulisan yang dikirimkan kepada pejabat diluar instansi sendiri sesuai dengan alamat yang dicantum pada tulisan dinas atau pada sampulnya.Selain dikirimkan kepada instansi lain, dapat juga dikirimkan kepada pihak yang bersangkutan dalam satu instansi, misalnya dikirimkan kepada bagian yang lainnya yang berada dalam instansi tersebut.

\section{Analisa Dan Perancangan Sistem}

\subsection{Analisa}

Dalam membuat website harus terlebih dahulu melakukan analisa dan rancangan. Tujuan dari adanya analisa dan perancangan adalah mempemrudah dalam pendataan surat masuk dan keluar berbasis website di Kelurahan Panjunan. Dalam Proyek Manajemen Informatika penulis akan membuat sebuah rancangan website Surat Masuk dan Surat Keluar di Kelurahan Panjunan. Oleh karena itu penulis akan menganalisis dengan baik agar dapat diimplementasikan dengan baik pula. Penulis akan merancang struktur dengan menggunakan data surat masuk, data surat keluar dan data surat undangan untuk pembuatan aplikasi yang akan dibangun, dengan menggunakan alur sistem secara keseluruhan dari sistem yang akan dibuat agar dapat mengidentifikasi dan mengatasi permasalahan-permasalahan yang terjadi.

3.2.

3.2.1

Flowmap Manual Flowmap Manual Surat Masuk

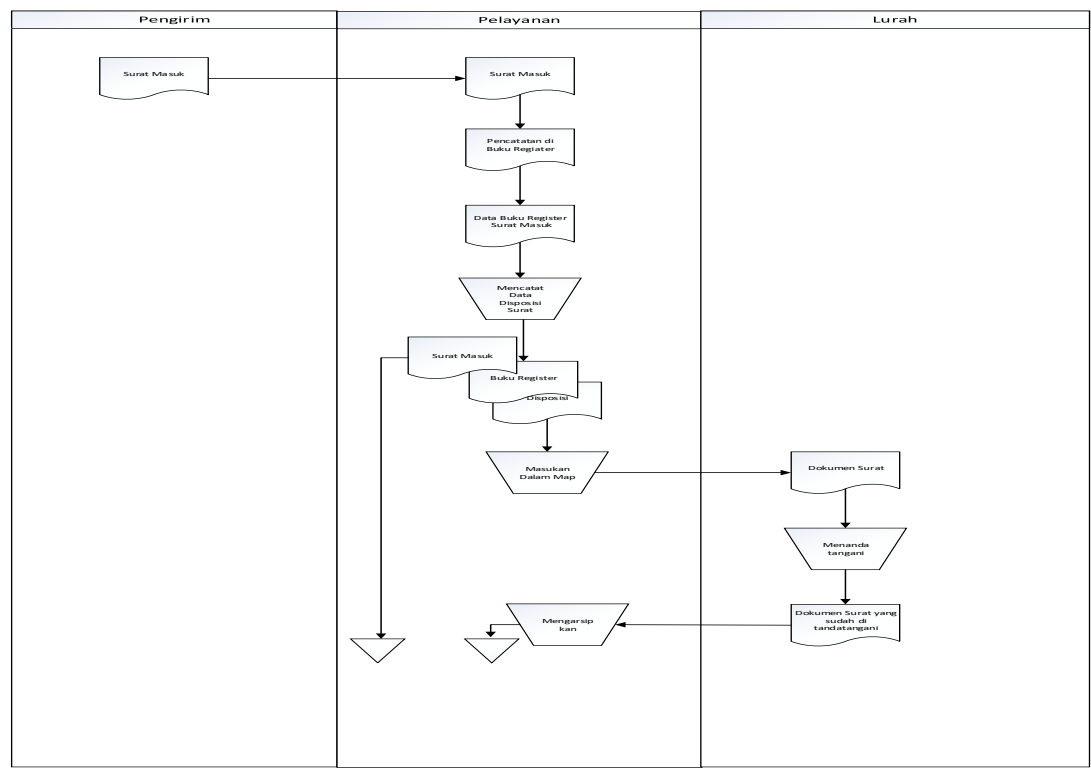

Gambar 1. Flowmap Surat Masuk

\subsubsection{Flowmap Manual Surat Keluar}

Sistem Aplikasi Website surat masuk dan keluar ( Studi kasus dikeluarahan panunan)-( Fairuz Maulana Rifani, Wiwiek Nurkomala Dewi, Agus Sevtiana) 


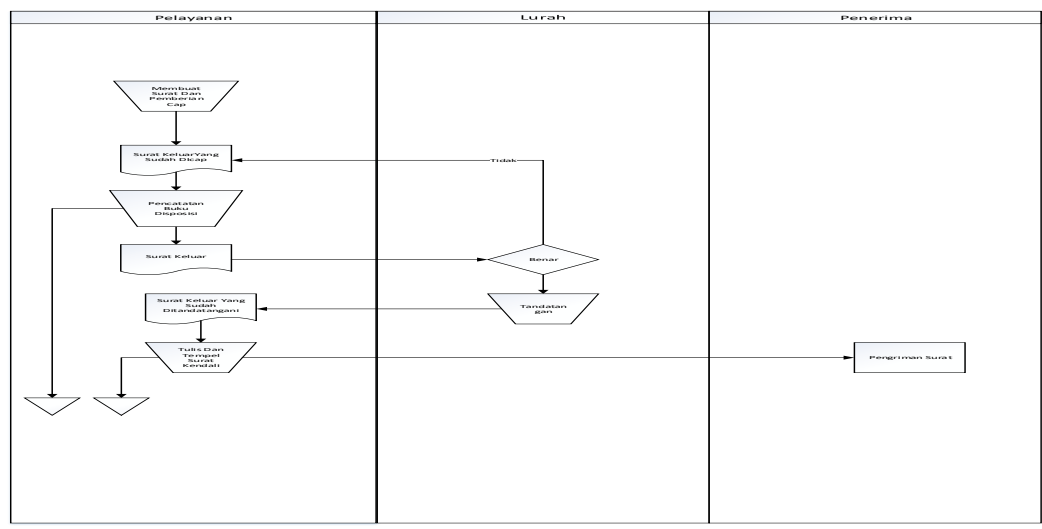

Gambar 2. Flowmap Surat Keluar

\subsection{Analisa Sistem Usulan}

Uraian hasil analisa flowmap manual memiliki kekurangan antara lain: proses pendataan kelahiran dan kematian hanya dicatat dalam buku, sulitnya mengetahui fluktuasi suratmasukdansuratkeluar di KelurahanPanjunan dari tahun ke tahun, oleh karena itu penulis membuat sistem usulan agar aplikasi ini dapat mempermudah proses pendataan kelahiran dan kematian yang ada di desa purbawinangun berbasis web.

\subsubsection{Sistem Pendataan Surat Masuk dan Surat Keluar Berbasis Website}

Sistem pendataan pada Kelurahan Panjunan hanya mencakup pendataan Surat Masuk dan Surat Keluar dengan menggunakan aplikasi web.

\subsubsection{Flowmap Usulan}

Flowmap usulan komputerisasi pendataan data Kelurahan Panjunan hanya mencakup pendataan Surat Masuk, SuratKeluar, SuratUndangan adalah sebagai berikut

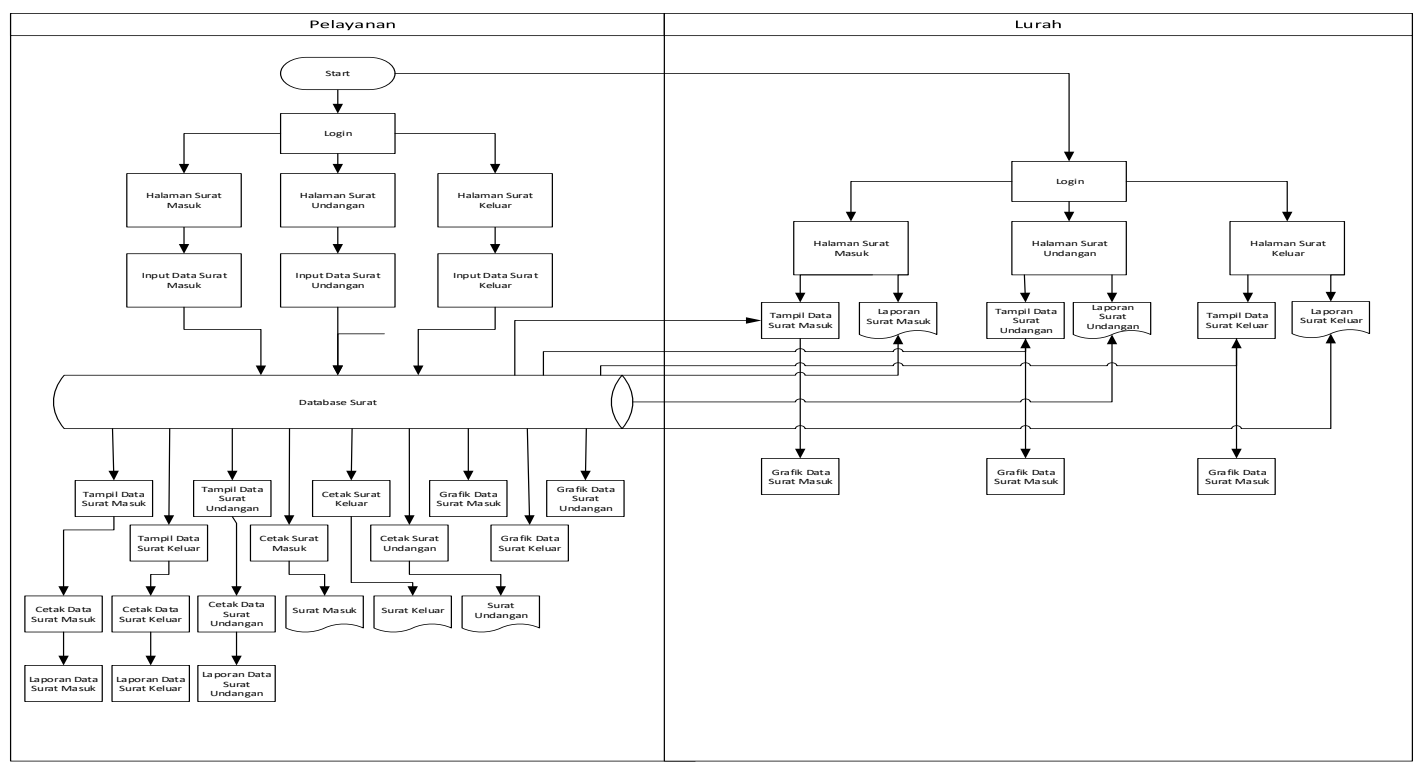

Gambar 3.Usulan Flowmap Data Surat 


\subsection{Diagram Sistem Usulan}

\subsubsection{Diagram Konteks Surat Masuk dan Keluar}

Diagram konteks adalah gambaran umum sebuah sistem, dibawah ini ladalah diagram usulan aplikasi data surat masukdan surat keluar di Kelurahan\Panjunanberbasis web adalah sebagai berikut:

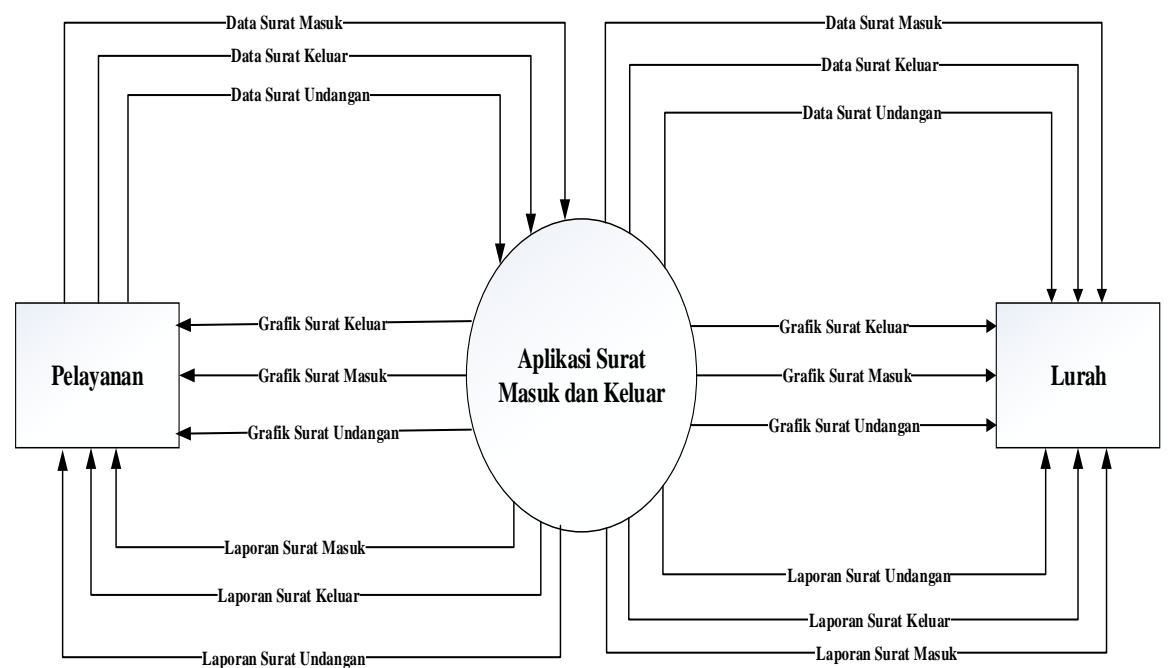

Gambar 4.Diagram Konteks Surat Masuk dan Surat Keluar

\subsubsection{Diagram Zero Surat}

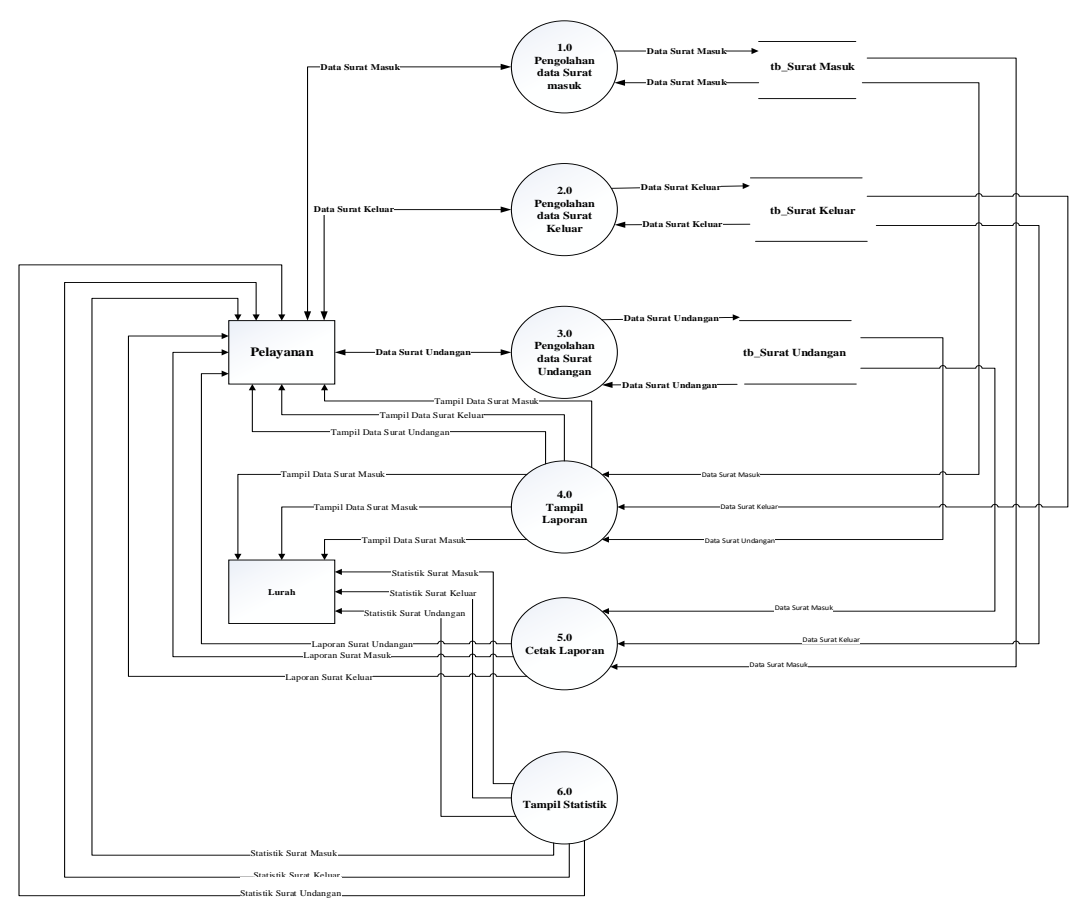

Gambar 5. Diagram Zero Surat

Sistem Aplikasi Website surat masuk dan keluar ( Studi kasus dikeluarahan panunan)-( Fairuz Maulana Rifani, Wiwiek Nurkomala Dewi, Agus Sevtiana) 


\subsection{Entity Relationship Diagram (ERD)}

Entity relationship diagram memiliki fungsi memberikan gambaran secara garis hubungan antar entitas pada sebuah sistem. Untuk memperjelas gambaran dari sebuah aktivitas entitas tersebut, pada entity relationship diagram setiap entitas yang ada digambarkan beserta dengan atribut-atributnya. Berikut ini adalah entity relationship diagram yang kami rancang dalam Data Surat Masuk dan Surat Keluar di KelurahanPanjunan Kota Cirebon Berbasis Website.

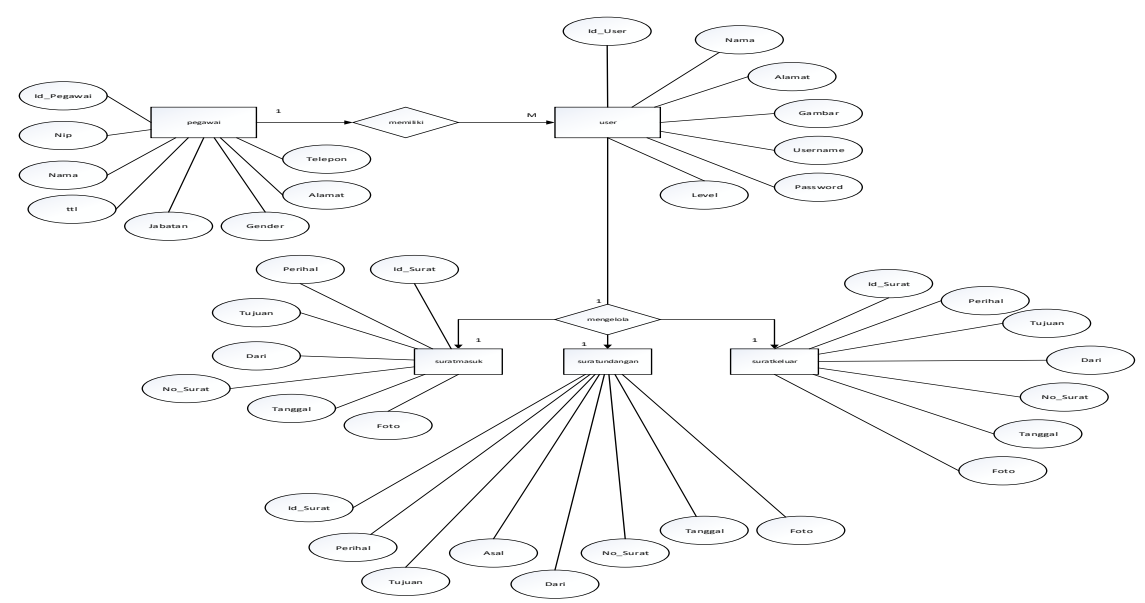

Gambar 6. ERD Surat

\subsection{Rancangan Sistem Usulan} Rancangan

1. Data Login User

2. Data Surat Masuk

3. Data Surat Keluar

4. Data Surat Undangan

\section{Implementasi Sistem}

Tahap implementasi adalah langkah pengujian sistem apakah bisa digunakan atau tidak secara benar. Kegiatan implementasi ini harus memenuhi syarat salah satunya tentang spesifikasi perangkat lunak dan spesifikasi perangkat keras.

\subsection{Tampilan Program}

Tahap akhir dari suatu program adalah tampilan program yang menerangkan bagaimana program aplikasi itu dapat dipakai oleh user seperti yang ditampilkan sebagai berikut ini :

\subsubsection{Form Login}

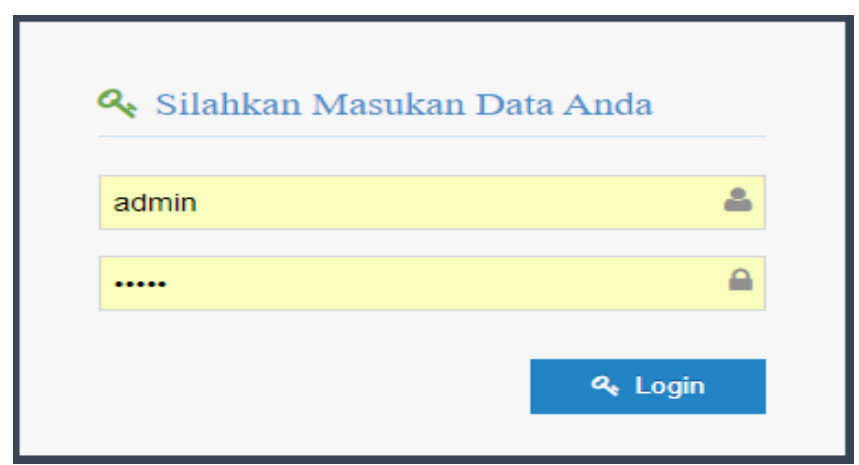

Gambar 7. Form Login 


\subsubsection{Menu Administrator}

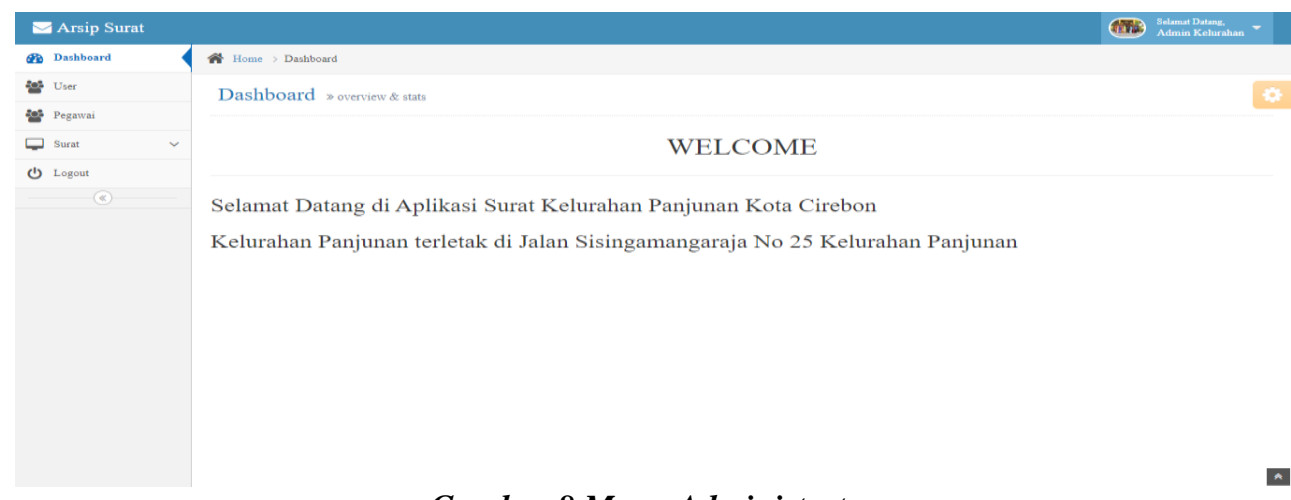

Gambar 8.Menu Administrator

\subsubsection{Menu Lurah}

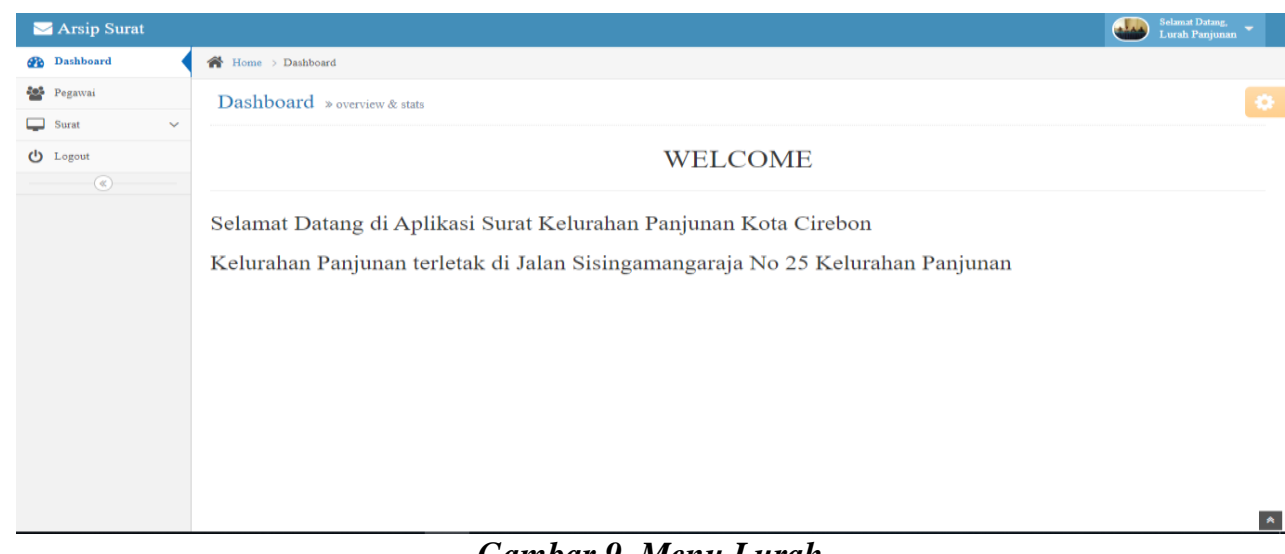

Gambar 9. Menu Lurah

\subsubsection{Form Input Data User}

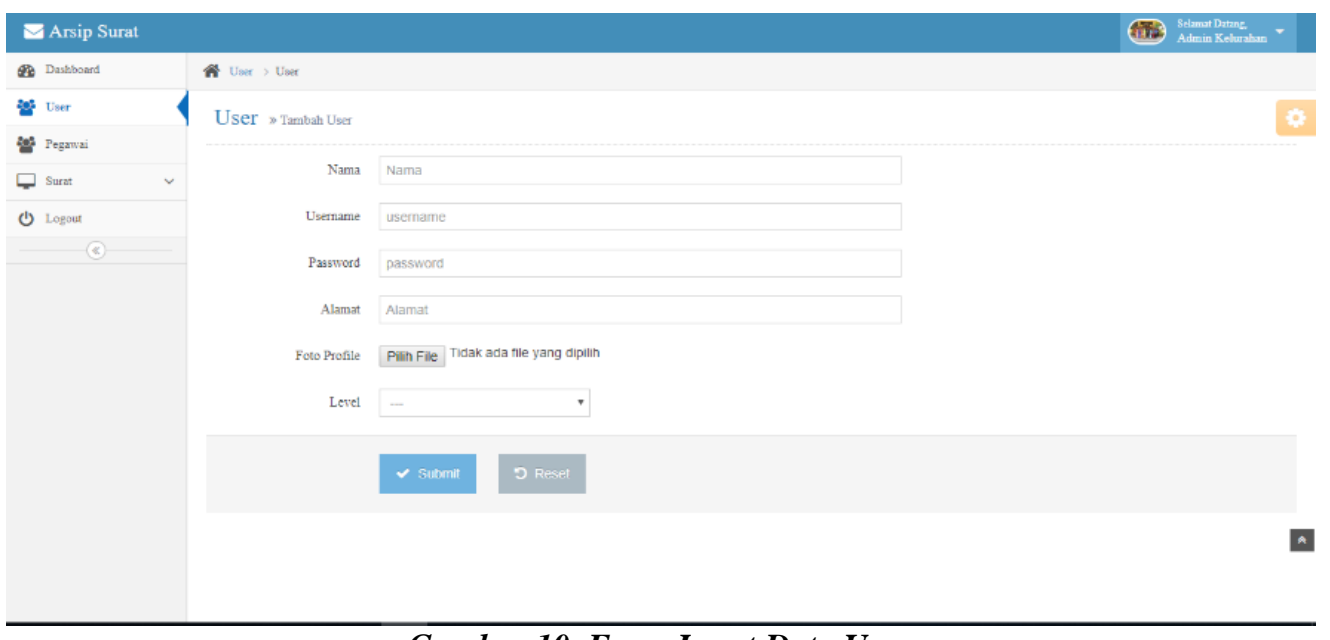

Gambar 10. Form Input Data User

Sistem Aplikasi Website surat masuk dan keluar ( Studi kasus dikeluarahan panunan)-( Fairuz Maulana Rifani, Wiwiek Nurkomala Dewi, Agus Sevtiana) 


\subsubsection{Form Input Data Pegawai}

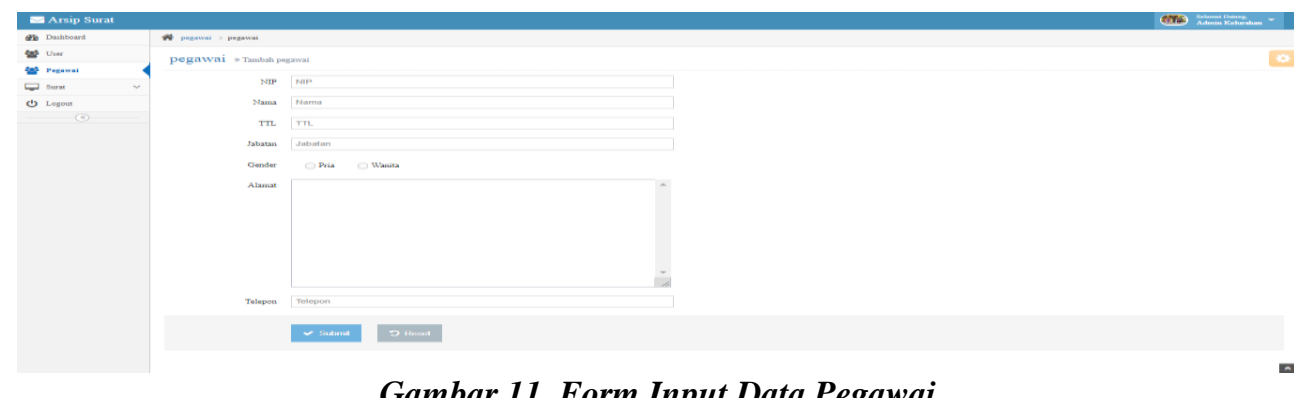

Gambar 11. Form Input Data Pegawai

\subsubsection{Form Input Data Surat Masuk}

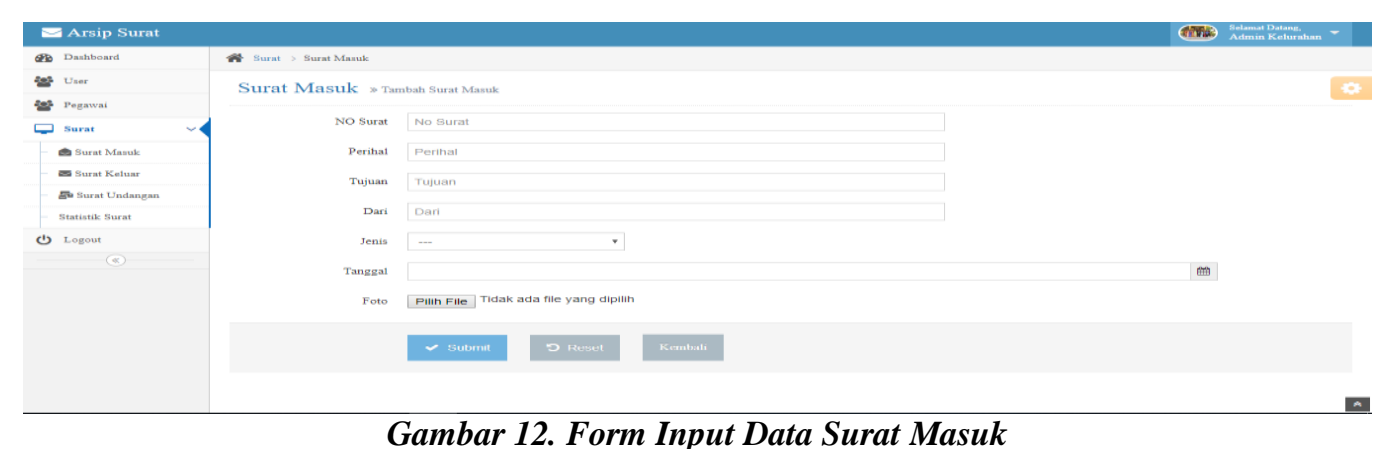

\subsubsection{Form Input Data Surat Keluar}

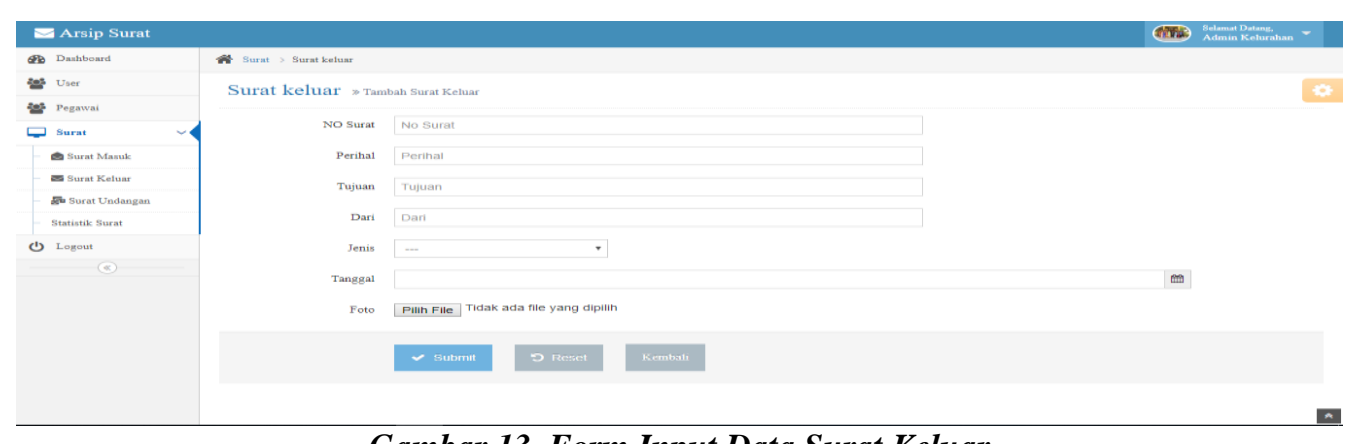

Gambar 13. Form Input Data Surat Keluar

4.1.8Form Input Data Surat Undangan

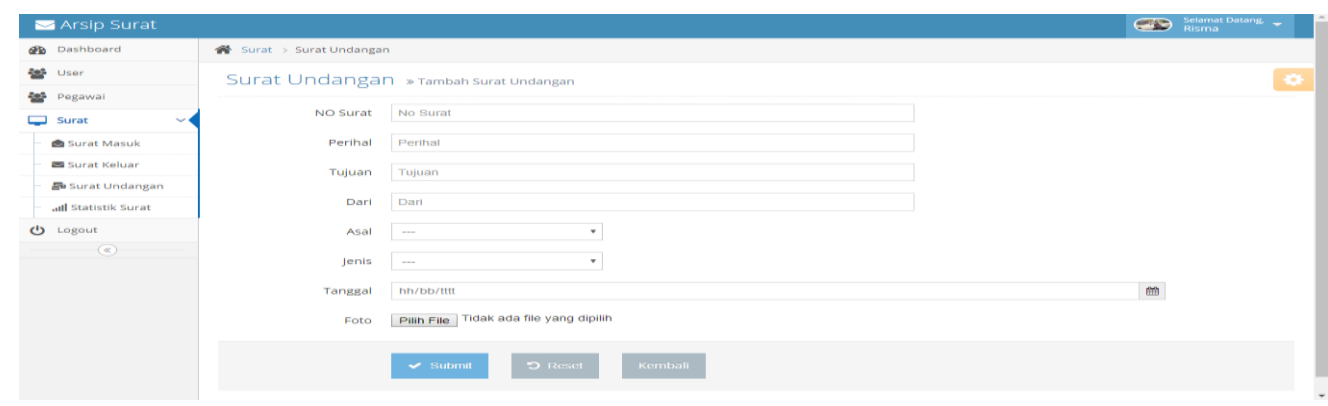

Gambar 14. Form Input Data Surat Undangan 


\subsubsection{Form Hasil Data Pegawai}

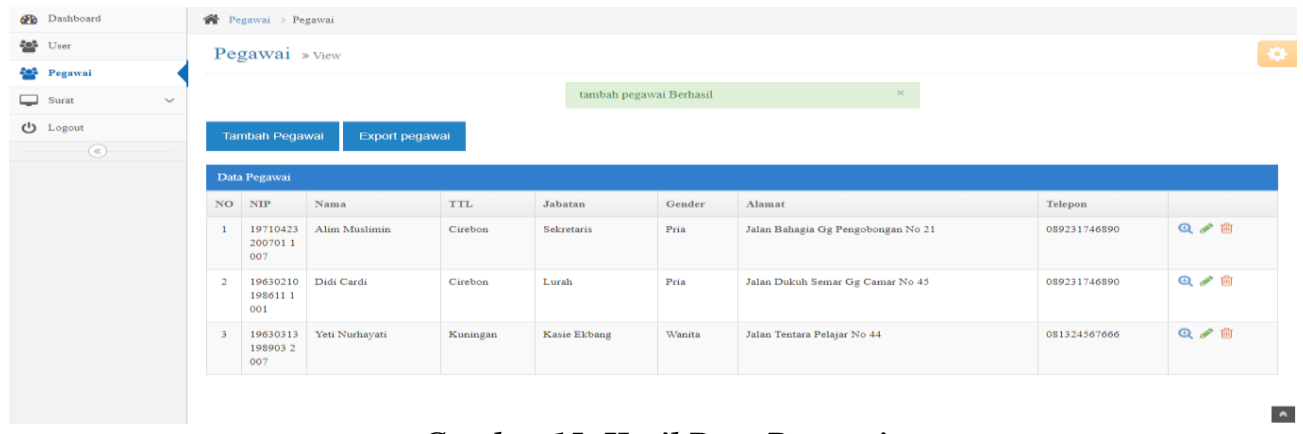

Gambar 15. Hasil Data Pegawai

4.1.10. Form Hasil Data Surat Masuk

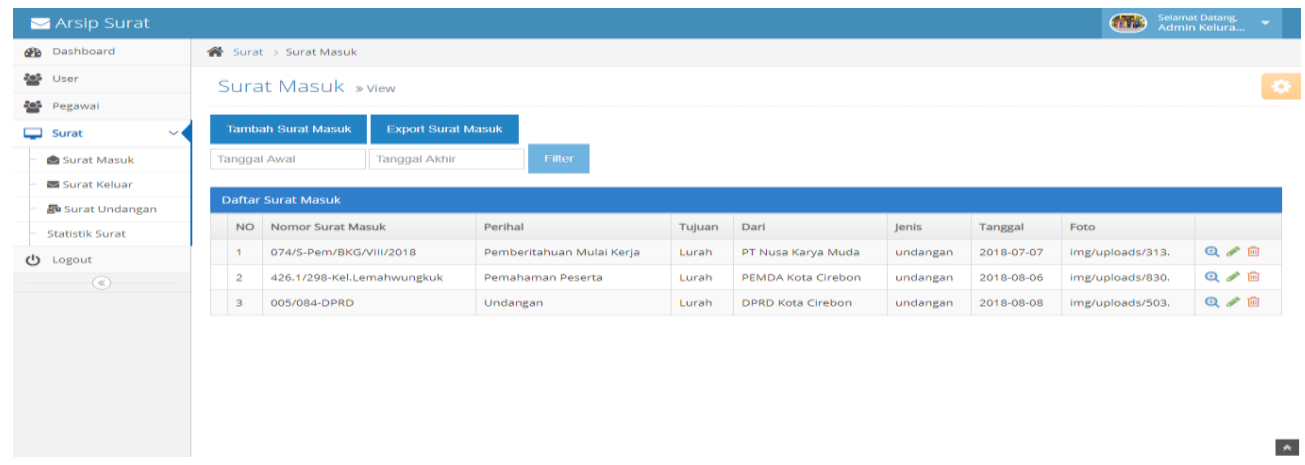

Gambar 16. Hasil Data Surat Masuk

\subsubsection{Form Hasil Data Surat Keluar}

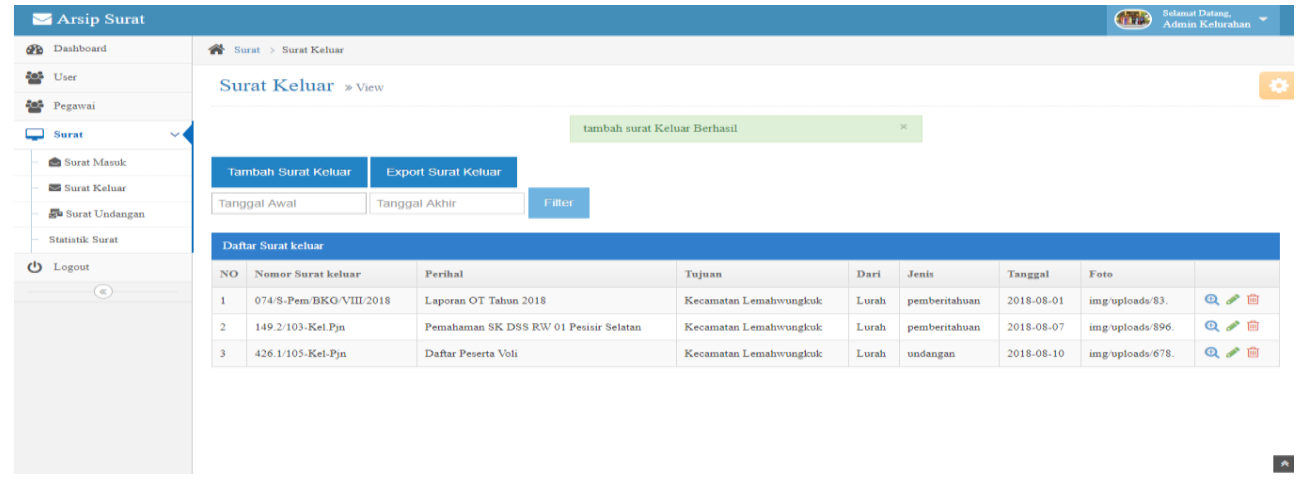

Gambar 17. Hasil Data Surat Keluar

Sistem Aplikasi Website surat masuk dan keluar ( Studi kasus dikeluarahan panunan)-( Fairuz Maulana Rifani, Wiwiek Nurkomala Dewi, Agus Sevtiana) 


\subsubsection{Form Hasil Data Surat Undangan}

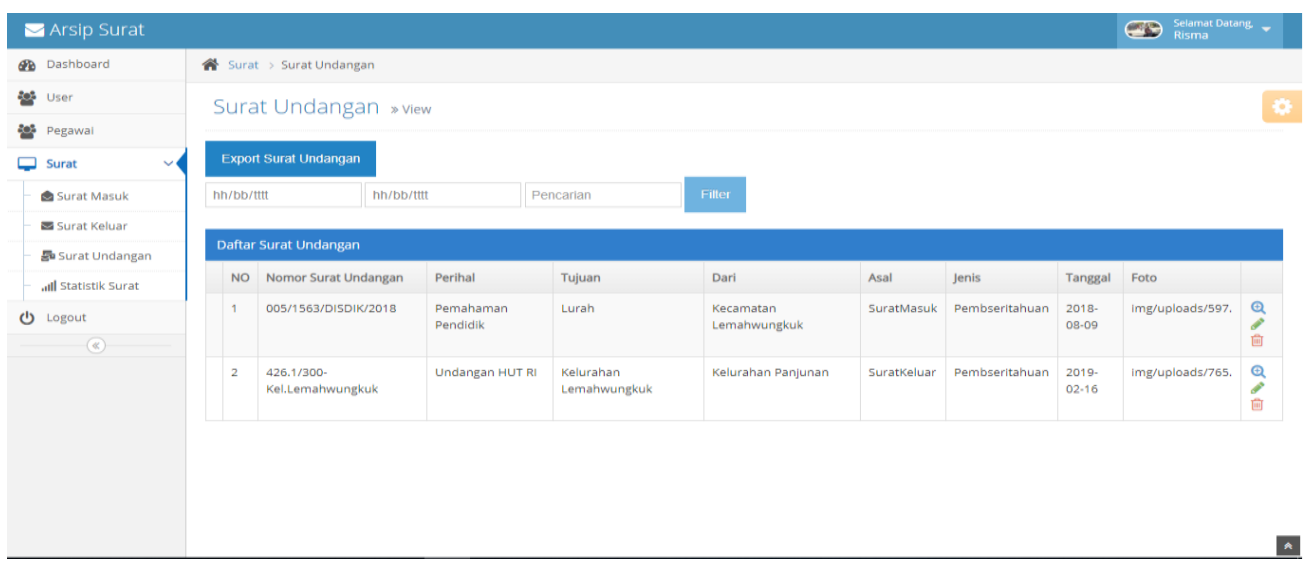

Gambar 18. Hasil Data Surat Undangan

\subsubsection{Form Hasil Data Surat Statistik}

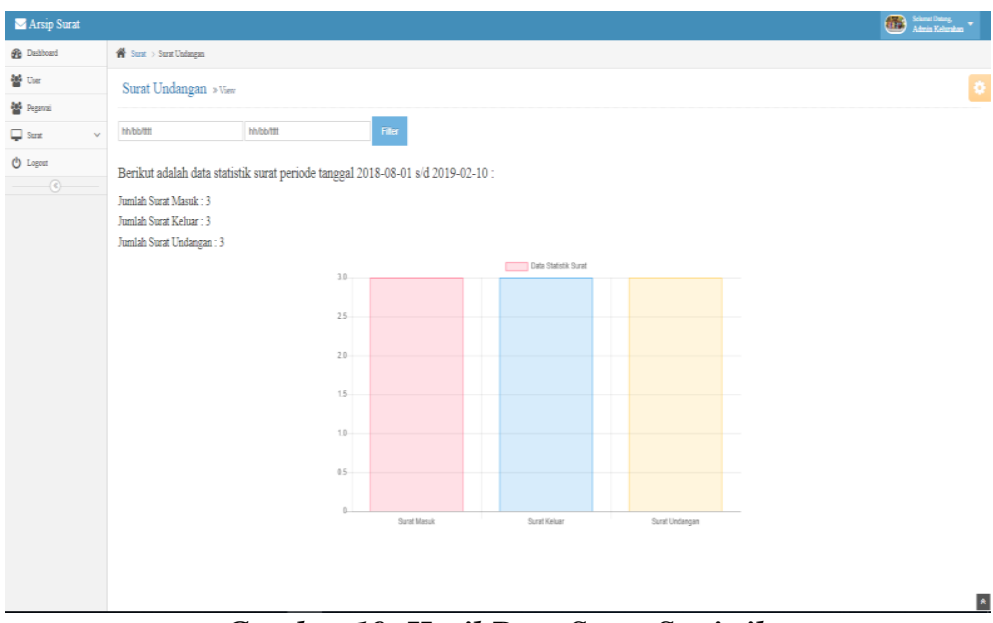

Gambar 19. Hasil Data Surat Statistik

\section{Kesimpulan Dan Saran}

\subsection{Kesimpulan}

Dari hasil penyusunan laporan dan pembuatan Aplikasi Pengelolaan Surat Masuk dan Keluar di Kelurahan Panjunan Cirebon, dapat disimpulkan sebagai berikut :

1. Dengan adanya aplikasi website Surat Masuk dan Surat Keluar Bagian Pelayanan tidak perlu mencatat dari buku register sehingga mudah dalam menghasilkan pendataan

2. Aplikasi pengelolaan surat mencegah kesalahan dalam penulisan manual yang sering tidak terbaca atau buku register yang kusam

3. Dengan adanya aplikasi website Surat Masuk dan Surat Keluar Bagian Pelayanan tidak perlu mencari dari buku register surat, hanya mencari data dari aplikasi

\subsection{Saran}

Berdasarkan dari kesimpulan dan penelitian di Kelurahan Panjunan, untuk mempermudah pengunaan aplikasi dan meningkatkan kinerja maka disarankan :

1. Sosialisasi penggunaan aplikasi kepada pihak yang terkait agar aplikasi dapat berjalan secara maksimal

2. Penambahan rancangan program agar bisa digunakan terus menerus

3. Bisa dikembangkan kembali kedalam platform yang lain 


\section{Daftar Pustaka}

[1] Agus Sugiartodan Teguh Wahyono, 2015. Manajemen Kearsipan Modern. Yogyakarta: Gava Media.

[2] Afra Tien Sotyaningrum, 2008. Korespondensi Bahasa Indonesia. Yogyakarta: Amara Books.

[3] Arief, M.Rudianto, 2011. Pemrograman Web Dinamis Menggunakan Php dan Mysq., Yogyakarta.

[4] Bagas Pratama dan Manurung, 2008. Surat Menyurat Midern Pustaka Setia. Bandung.

[5] Badri Munir Sukoco, 2008. Manajemen Administrasi Perkantoran. Jakarta: Modern Erlangga.

[6] Bektidan Bintu Humairah, 2015. Mahir Membuat Website dengan Adobe Dreamweaver CS6, CSS dan JQuery. Yogyakarta.

[7] Dewi, Irra Chrisyanti. 2011. Pengantar Ilmu Administrasi. Jakarta: PT Prestasi Pustakaraya.

[8] Djihad Hisyam, 2008. Koresponden Bahasa Dalam Teori dan praktik. Yogyakarta: UNYpress.

[9] Drs. Basir Barthos, 2013. Manajemen Kearsipan. Jakarta: Bumi Aksara.

[10] Djoko Purwanto, 2010. Komunikasi Bisnis. Jakarta: Erlangga.

[11] Ida Nuraida, 2014. Manajemen Administrasi Perkantoran Edisi Revisi. Jakarta: Kanisius.

[12] Lamuddin Finoza, 2013. Komposisi Bahasa Indonesia untuk Mahasiswa Nonjurusan Bahasa. Jakarta Diksi Insan Mulia.

[13] Rosa A.S dan M. Shalahuddin, 2011. Modul Pembelajaran Rekayasa Perangkat Lunak Terstruktur dan Berorientasi Objek., Bandung.

[14] Sondang P. Siagian, 2014. Falsafat Administras. Jakarta: Bumi Aksara. The Liang Gie, 2009. A dministrasi Perkantoran Modern, Yogyakarta.

[15] Wursanto, 2017. The Lunguinstic Studen't handbook. Bogor: Media Wacana.

[16] Yakub, 2012. Pengantar Sistem Informasi. Yogyakarta: Graha Ilmu. 